This script file intended to accompany: Koopman, Howe, Hollenbeck \& Sin. Small Sample Mediation Testing: Misplaced Confidence in Bootstrapped Confidence Intervals.

\title{
To utilize:
}

- Save this script file on your computer

- R script files use a .R extension, but can be viewed in any text editor (e.g. MS Notepad

- Download and install R (http://cran.r-project.org/)

- Install required packages from within R: "boot", "coda", "nlme", "MCMCpack", "psych“

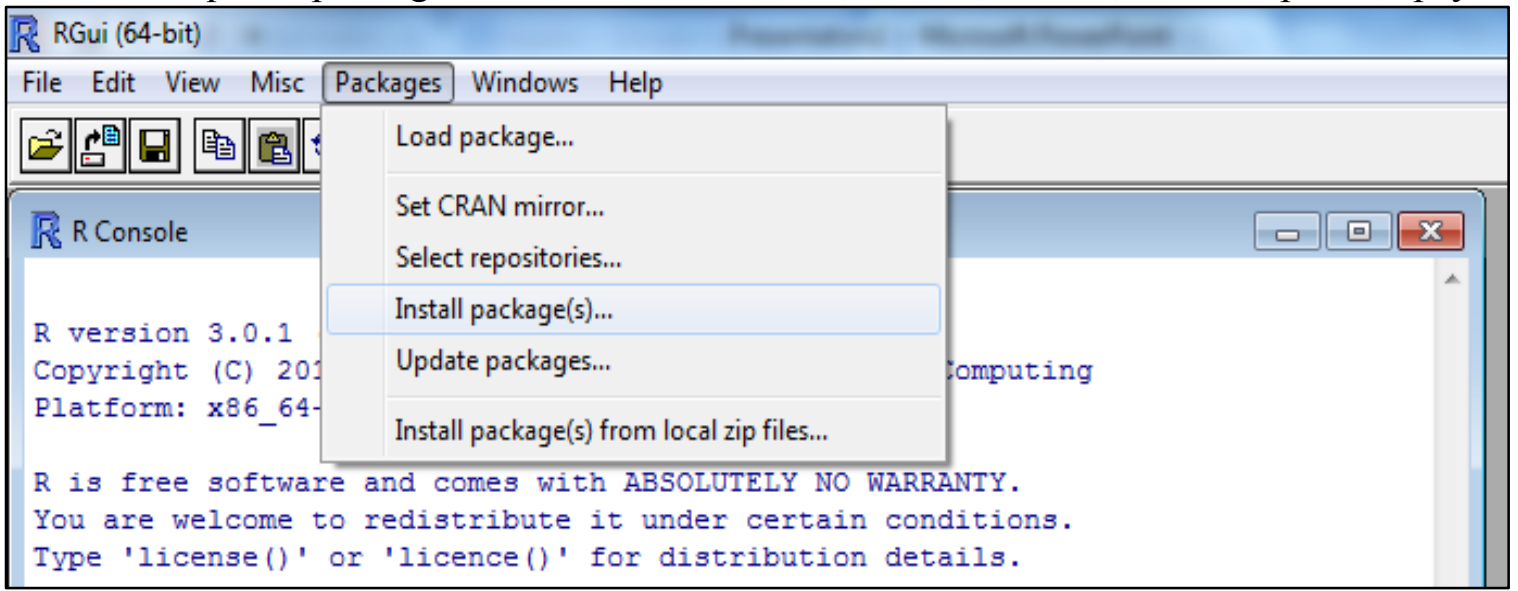

- Open the script file in $\mathrm{R}$

\begin{tabular}{|l|l|}
\hline File RGui (64-bit) \\
\hline $\begin{array}{l}\text { Source R code... } \\
\text { New script }\end{array}$ \\
\hline $\begin{array}{l}\text { Open script... } \\
\text { Display file(s)... } \\
\text { Load Workspace... } \\
\text { Save Workspace... }\end{array} \quad \begin{array}{l}05-16)-- \text { "Good Sport" } \\
\text { R Foundation for Statistical Computing } \\
\text { ingw32/x64 (64-bit) } \\
\text { Load History... } \\
\text { Save History... } \\
\text { comes with ABSOLUTELY No WARRANTY. } \\
\text { istribute it under certain conditions. } \\
\text { icence ()' for distribution details. }\end{array}$ \\
\hline
\end{tabular}

- Modify the script as necessary for your data (see comments within script)

- Highlight the script (all or part) and execute

File Edit Packages Windows Help
$\mathrm{R}$ version 3.0 .1 (2013-05-16) -- "Good Sport"
Copyright (C) 2013 The R Foundation for Statistical Computing
Platform: x86_64-w64-mingw32/x64 (64-bit)
R is free software and comes with ABSOLUTELY No wARRANTY.
You are welcome to redistribute it under certain conditions.
Type 'license()' or 'licence()' for distribution details.

